\title{
Prevalence and determinants of microalbuminuria among diabetic patients in the United Arab Emirates Fatma Al-Maskari*1, Mohammed El-Sadig ${ }^{1}$ and Enyioma Obineche ${ }^{2}$
}

\author{
Address: ${ }^{1}$ Department of Community Medicine, Faculty of Medicine \& Health Sciences, Al-Ain City, United Arab Emirates University, PO Box: \\ 17666, UAE and 2 Department of Internal Medicine, Faculty of Medicine \& Health Sciences, Al-Ain City, United Arab Emirates University, PO Box: \\ 17666, UAE \\ Email: Fatma Al-Maskari* - fatma.am@uaeu.ac.ae; Mohammed El-Sadig - msadig@uaeu.ac.ae; Enyioma Obineche - eobineche@uaeu.ac.ae \\ * Corresponding author
}

Published: 29 January 2008

BMC Nephrology 2008, 9:1 doi:10.1 186/1471-2369-9-I
Received: 6 May 2007

Accepted: 29 January 2008

This article is available from: http://www.biomedcentral.com/I47/-2369/9/I

(c) 2008 Al-Maskari et al; licensee BioMed Central Ltd.

This is an Open Access article distributed under the terms of the Creative Commons Attribution License (http://creativecommons.org/licenses/by/2.0), which permits unrestricted use, distribution, and reproduction in any medium, provided the original work is properly cited.

\begin{abstract}
Background: Microalbuminuria (MA) represents the earliest clinical evidence of diabetic nephropathy and is a predictor of increased cardiovascular morbidity and mortality. The aim of this study was to determine the prevalence of MA among diabetic patients in the Al-Ain district of the United Arab Emirates (UAE).

Methods: The study was part of a general cross-sectional survey carried out to assess the prevalence of diabetes mellitus (DM) complications in Al-Ain district, UAE and was the first to assess the prevalence of $M A$ among diabetic patients. A sample of $5 / 3$ diabetic patients with a mean age of 53 years (SD: \pm 13) was randomly selected during 2003/2004. All patients completed an interviewer-administered questionnaire and underwent medical assessment. First morning urine collections were obtained and were tested for clinical proteinuria using urine dipsticks and for MA using the single Micral-Test II strips.

Results: MA was found in $61 \%(95 \% \mathrm{Cl}: 56.7-65.7)$ of the sample and the rate was significantly higher among males, positively related to body mass index (BMI), type $2 \mathrm{DM}$ and presence of other DM complications such as diabetic retinopathy and neuropathy. Of the total sample population, 12.5\% (95\% Cl: 8. I-I4.I) had clinical proteinuria.

Conclusion: The prevalence rate of MA was considerably high ( $61 \%$ ) among diabetic patients in the UAE. Therefore, regular screening for MA is recommended for all diabetic patients, as early treatment is critical for reducing cardiovascular risks and slowing the progression to late stages of diabetic nephropathy (overt proteinuria and end-stage renal disease).
\end{abstract}

\section{Background}

Diabetes mellitus (DM) has long been recognized as a major public health problem with far reaching consequences, not only for its adverse health impact on individuals, but also for its economic burden on the health care system and the society at large [1]. The International Diabetes Federation (IDF) in 2005 confirmed that diabetes is one of the most common non-communicable diseases globally and constitutes the fourth or fifth leading cause of death in most developed countries as well as many developing and newly industrialized countries, such as the United Arab Emirates (UAE) [2]. The IDF in 2003 ranked the UAE's prevalence rate for type 2 DM and IGT 
as the second highest in the world (20\% for DM and $26 \%$ for IGT) [2].

Diabetic nephropathy is characterized by proteinuria and is widely considered as the leading cause of end-stage renal disease (ESRD) which constitutes the major workload of dialysis centers worldwide. Indeed, the costs of dialysis and renal transplantation imposed by ESRD implicate a sizeable burden on health care resources [3] and seriously compromise both the quality of life and life expectancy [4-7]. It is well known that progression to established diabetic nephropathy occurs through several stages. MA, defined as urinary albumin excretion rate of 20-200 ug/min on a timed specimen without an alternative clinical explanation (such as urinary tract infection, heart failure or exercise in the past 48 hours) or urinary protein excretion rate of $30-300 \mathrm{ug} / \mathrm{min}$, is a known predictor of future developments of overt diabetic nephropathy [8]. Because MA can be reversed and the future developments of overt diabetic nephropathy can be significantly reduced, screening for MA and the timely therapeutic intervention has become the standards of care worldwide.

Screening for MA can be performed using quantitative methods, including: i) measurement of albumin to creatinine ratios in a random urine sample; ii) a 24 -hour collection with creatinine, allowing the simultaneous measurement of creatinine clearance; iii) timed (e.g. 4 hour) overnight urine collection for protein, or by using semi-quantitative reagent dipsticks specifically designed with detection limits suitable for identifying microalbuminuria, such as the Micral dipsticks [9].

According to the American Diabetes Association (ADA), when using the random collection technique, normal albumin excretion should be defined as $<30 \mathrm{mcg} / \mathrm{mg}$ of creatinine; microalbuminuria 30 to $299 \mathrm{mcg} / \mathrm{mg}$ of creatinine, and macroalbuminuria is $300>\mathrm{mcg} / \mathrm{mg}$ of creatinine [10]. In the 24-hour collection technique, albumin excretion $<30 \mathrm{mg}$ per 24 hours is considered normal, 30 to $299 \mathrm{mg}$ per 24 hours indicates microalbuminuria, and $300 \mathrm{mg}$ or higher indicates macroalbuminuria [10]. When using the timed collection technique, normal albumin excretion is defined as $<20 \mathrm{mcg} / \mathrm{min}$, microalbuminuria is defined as 20 to $199 \mathrm{mcg} / \mathrm{min}$, and macroalbuminuria as $200>\mathrm{mcg} / \mathrm{min}[10]$.

Screening for MA with Micral-test II strips is relatively cheap, fast and has an acceptable sensitivity of $97 \%$ with a specificity of $71 \%$ [9]. Several studies comparing Micral test II and laboratory methods of detecting albuminuria have concluded that the test could be used as a screening tool but, because of its low specificity, cannot be used as a diagnostic tool [11-13]. Micral test II is an optically read immunoassay, specifically designed for detection of MA and the use of these strips has been widely advocated [9].

Generally, screening for MA is relatively cheap and convenient procedure to detect MA among diabetic patients to reduce cardiovascular risks and the rate of progression of diabetes-related nephropathy. To our best knowledge our study constitutes the first effort in the UAE to estimate the prevalence of MA among patients with diabetes mellitus.

\section{Methods \\ Overall design}

The study was part of a general cross-sectional survey of DM patients carried out to assess and establish the prevalence of DM complications including MA among diabetic patients in Al-Ain District, UAE, using the single MicralTest II strips.

\section{Subjects and setting}

The sampling frame of this study included all nationals and non-nationals diabetic patients of all ages and both genders attending any primary health care center (PHCC) for any reason and diabetic clinics at hospitals for follow up in Al-Ain district of Abu Dhabi. Power and sample estimations were used to estimate a sample size with a standard error of $2 \%$. Accordingly, a sample size of 625 patients was estimated. To achieve that all PHCC and diabetic clinics in the district were enlisted and enumerated and multistage random sampling was used to select 8 PHCC (a proportion of $25 \%$ out of 22 rural and urban PHCC) in addition to two diabetic clinics at the two main public hospitals in Al-Ain district. In the absence of a diabetes registry or a computerized database for patients in the district, systematic random sampling was used to select patients to be approached for participation in the study. Therefore, every third DM patient visiting the participant PHCC and diabetic clinics was approached. In total, 600 patients were approached by general practitioners and diabetologists, out of which 513 patients (86\%) agreed to enroll. The study was approved by the Joint Ethics Committee of the Faculty of Medicine and Health Sciences of the UAE University and the Al-Ain Medical District. The data were collected between September 2003 and May 2004.

\section{Data collection}

After receiving a prior informed consent (a written one from literate patients and a verbally informed one from illiterate patients), participant patients were interviewed by their treating doctors about DM type, duration, treatment profile, level of control, presence or absence of chronic DM complications. The diagnosis of diabetes was based on self reported physician diagnosis of diabetes. Participants who were not responding to oral hypoglyc- 
emic agents and needed insulin treatment within two years of diagnosis were classified as having type 1 diabetes. All other cases were classified as type 2 diabetes.

Blood pressure (BP) was measured early in the morning and prior to drawing of blood samples using a suitable mercury sphygmomanometer after a 10 minutes rest with the patient in the sitting position. BP was measured two times at 5 minutes interval. The first and the fifth korotokoffs sound were used to determine the systolic and diastolic blood pressure measurement, respectively. The second blood pressure measurement was used as the blood pressure for the individual. The WHO definition of hypertension was used in this study: systolic blood pressure $160 \mathrm{mmHg}$ or more and/or a diastolic blood pressure $95 \mathrm{mmHg}$ or more [14], or if the patient is on treatment with antihypertensive drugs. Height was measured without shoes, and weight was recorded while wearing indoor clothing. Body mass index (BMI) (weight in $\mathrm{Kg}$, divided by height in meters squared) was calculated. The WHO $(1995,2002)$ classification for BMI was used to estimate the degree of obesity [15]. A standard 12-lead electrocardiogram (ECG) was recorded for all patients. Fasting blood samples were taken to assess lipid profile, blood sugar and glycated hemoglobin $\left(\mathrm{HbA}_{1 \mathrm{C}}\right)$ levels. Total lipid profile (total cholesterol (TC), high density lipoprotein (HDL), TC/HDL ratio, low density lipoprotein (LDL) and triglycerides) was measured by a capillary tube whole blood method using the Cholesterol LDX lipid analyzer. Dyslipidaemia was taken to be present when the total cholesterol was $>5.60 \mathrm{mmol} / \mathrm{L}$ and/or triglycerides $>2.10$ $\mathrm{mmol} / \mathrm{L}, \mathrm{LDL}>3.4 \mathrm{mmol} / \mathrm{L}$, and/or HDL $<0.91 \mathrm{mmol} / \mathrm{L}$. Fasting blood glucose was measured by glucose oxidase method; Clinical Chemistry Analyzer. Glycated haemoglobin $\left(\mathrm{HbA}_{1 \mathrm{C}}\right)$ was measured using the Bayer DCA $2000+$ analyzer and a value of less than $7 \%$ was taken to indicate good glycemic control.

The diagnosis of diabetic nephropathy was made when MA and/or clinical proteinuria was detected and other causes of kidney disease or alternative explanations for proteinuria such as urinary tract infection (UTI), marked hypertension, heart failure and febrile illness were excluded. Patients who had undergone renal transplantation or were treated with dialysis with no other reason for renal failure were also considered to have diabetic nephropathy. Proteinuria was defined by the presence of protein in the urine using the conventional test strips (Redia, Boehringer-Mannheim, Mannheim, Germany). Two categories of proteinuria were identified: severe level; in those with heavy proteinuria $(\geq 3+)$; and trace or intermediate level in those who had $(<3+)$ urinary protein. Urinary albumin concentration was measured by using semiquantitative dry immuno chemical screening strips (Micral II ${ }^{\circledR}$ test strips (Roche diagnostic GmbH Man- nheim Germany). Micral Tests were performed on first morning urine collections and a value of more than 20 $\mu \mathrm{g} / \mathrm{min}$ was judged as pathological. Chronic renal failure was defined by a serum creatinine level $>3 \mathrm{mg} / \mathrm{dL}$ [16].

Cardiovascular complications were ascertained using standard procedures. Coronary artery disease was identified by symptoms of definite angina pectoris or of definite past myocardial infarction and/or ECG changes consistent with previous myocardial infarction. Peripheral neuropathy was determined by Diabetic Neuropathy Symptoms (DNS) [17] and the Diabetic Neuropathy Examination (DNE) scores [18]. Neuropathy was considered to be present if DNS score was $>0$ and/or the DNE score was $>3$. The presence of retinopathy was confirmed by fundus photography using digital camera.

\section{Statistical analysis}

The data was coded and processed on IBM compatible computers, using the Statistical Package for Social Sciences (SPSS) software (version 14). Descriptive analysis, using standard statistical methods was performed. Chisquare tests or Fisher's exact test, independent t-tests and Pearson correlation coefficient were used to ascertain the association between MA and clinical outcome variables.

A multiple logistic regression model with backward selection (criterion: probability of $F$ to remove $\geq 0.10$ ) was used to estimate the effect of microalbuminuria (MA) among the sample population. The method enters all independent variables in the equation and then sequentially removes them. The variable with the smallest partial correlation with the dependent variable $\left(Y_{i}\right)$ is considered first for removal. If it meets the criterion for elimination, it is removed. After the first variable is removed, the variable with the smallest partial correlation remaining in the equation is considered next. The procedure stops when there are no variables in the equation that satisfy the removal criterion.

The variables included as predictors were: sex, type of DM, age group, duration of disease (in years), nationality and BMI group. That is in addition to a number of determinants of dichotomous (yes/no) outcomes related to DM including presence of coronary artery disease, diabetic retinopathy and neuropathy. Missing values for variables were replaced with the variable mean. ANOVA was used to estimate overall and individual significance of regression parameters. For overall significance the test statistic $F$ was used to test parameters $B_{i j}$ for significance. For individual parameters the $t$-test was used. According to principles, the overall significance of the model was used as evidence for the suitability of the model. 


\section{Results}

Socio-demographic characteristics of the study population A total sample $(n=600)$ of male and female diabetic patients of all nationalities (UAE nationals and expatriates) resident in the Al-Ain district of Abu Dhabi emirate was selected; of whom, 513 agreed to enroll. Of the total sample, $52 \%$ were males, $27 \%$ aged 60 or above, $75 \%$ were UAE nationals and most patients (63\%) were illiterate. Of the total sample 13\% (95\% CI: 11.0-14.6) were currently smoking while $8.2 \%$ (95\%CI: 6.7-9.7) were exsmokers and $76 \%$ were obese or overweight (Table 1).

\section{Clinical characteristics}

The majority of the sample population (86\%) had Type 2 DM; $49 \%$ were diagnosed incidentally and most of them (79\%) had been diabetic for $\geq 10$ years. Of the total population, 35\% (95\%CI: 30.8-39) had hypertension. The majority of patients ( $84 \%$ ) were partially managed by oral hypoglycemic agents, $24 \%$ by insulin while two thirds were not following any exercise regime as part of their DM management. The analysis of glycemic control of patients using $\mathrm{HbA}_{1 \mathrm{C}}$ showed that 38\% (95\%CI: 32.8-42.4)) had good glycemic control (Table 2). Dyslipidaemia, assessed by elevated total cholesterol, was present in 34\% (95\%CI:

Table I: Baseline Characteristics of DM Patients in AI-Ain District, UAE, 2003-2004 ( $n=5$ I 3)

\begin{tabular}{|c|c|c|}
\hline \multirow[t]{2}{*}{ Variable name } & \multicolumn{2}{|c|}{ Prevalence of DM } \\
\hline & $\mathbf{n}$ & Percent (95\% CI) \\
\hline \multicolumn{3}{|l|}{ Sex } \\
\hline Male & 264 & $51.5(47.2-55.8)$ \\
\hline Female & 249 & $48.5(44.2-52.8)$ \\
\hline \multicolumn{3}{|l|}{ Level of Education } \\
\hline Illiterate & 318 & $62.8(58.6-67.0)$ \\
\hline Completed primary school & 99 & $19.6(16.1-23.1)$ \\
\hline Completed secondary school & 60 & $11.9(9.1-14.7)$ \\
\hline Completed university & 29 & $5.7(3.7-7.7)$ \\
\hline \multicolumn{3}{|l|}{ Age group (Years) } \\
\hline 40 or less & 81 & $15.8(12.6-19.0)$ \\
\hline $4 I-49$ & 137 & $26.8(23-30.6)$ \\
\hline $50-59$ & 154 & 30.1 (26.I-34.I) \\
\hline 60 or above & 140 & $27.3(23.4-31.2)$ \\
\hline \multicolumn{3}{|l|}{ Nationality group } \\
\hline UAE & 382 & $74.6(70.8-78.4)$ \\
\hline Other Gulf countries citizens & 54 & $10.5(7.8-13.2)$ \\
\hline Arabs from other countries & 54 & $10.5(7.8-13.2)$ \\
\hline Asians & 22 & $4.3(2.5-6.1)$ \\
\hline \multicolumn{3}{|l|}{ Smoking } \\
\hline Current smoker & 64 & $12.8(11.0-14.6)$ \\
\hline Ex smoker & 41 & $8.2(6.7-9.7)$ \\
\hline \multicolumn{3}{|l|}{ BMI Group } \\
\hline Under weight $(<\mid 8.5)$ & 6 & $1.2(0.2-2.2)$ \\
\hline Healthy weight (18.5-24.99) & 113 & $22.5(18.8-26.2)$ \\
\hline Overweight (25-29.99) & 195 & $38.8(34.5-43.1)$ \\
\hline Obese $(>30)$ & 188 & $37.7(33.3-41.7)$ \\
\hline
\end{tabular}

Table 2: Clinical Characteristics of DM Patients in Al Ain District, UAE, 2003-2004 $(n=513)$

\begin{tabular}{|c|c|c|}
\hline & $n$ & Percent $(95 \% \mathrm{Cl})$ \\
\hline \multicolumn{3}{|l|}{ Type of DM } \\
\hline Type I & 68 & $13.6(10.6-16.6)$ \\
\hline Type 2 & 431 & $86.4(83.4-89.4)$ \\
\hline \multicolumn{3}{|l|}{ Mode of Diagnosis } \\
\hline Incidental & 245 & $48.5(44.1-52.9)$ \\
\hline Screening & 39 & $7.7(5.4-10.0)$ \\
\hline Symptomatic & 221 & $43.8(39.5-48.1)$ \\
\hline \multicolumn{3}{|c|}{ Family History of DM } \\
\hline Present & 270 & $54.3(49.9-58.7)$ \\
\hline \multicolumn{3}{|c|}{ Duration of the Disease } \\
\hline$<$ I year & 33 & $6.6(4.4-8.8)$ \\
\hline $\mathrm{I}-5$ years & 199 & $40.0(35.7-44.3)$ \\
\hline $6-10$ years & 161 & $32.3(28.2-36.4)$ \\
\hline II-20 years & 98 & $19.7(16.2-23.4)$ \\
\hline$>21$ years & 7 & $1.4(0.4-2.4)$ \\
\hline \multicolumn{3}{|l|}{ Hypertension } \\
\hline Present & 178 & $34.9(30.0-38.8)$ \\
\hline \multicolumn{3}{|l|}{ Total Cholesterol } \\
\hline High (>5.60 mmol/L) & 152 & $34.4(30.0-38.8)$ \\
\hline \multicolumn{3}{|l|}{ Triglycerides } \\
\hline High (>2.10 mmol/L) & 105 & $23.9(19.9-27.9)$ \\
\hline \multicolumn{3}{|l|}{ HDL } \\
\hline Low (<0.91 mmol/L) & 36 & $25.7(18.5-32.9)$ \\
\hline \multicolumn{3}{|l|}{ LDL } \\
\hline High (>3.4 mmol/L) & 70 & 53.4(44.9-61.9) \\
\hline \multicolumn{3}{|l|}{ Microalbuminuria } \\
\hline Present (>20 $\mu \mathrm{g} / \mathrm{min})$ & 276 & $61.2(56.7-65.7)$ \\
\hline \multicolumn{3}{|l|}{$\mathrm{HBA}_{1} \mathrm{C}$} \\
\hline Good control (<7\%) & 150 & $37.6(32.8-42.4)$ \\
\hline Poor control (>7\%) & 246 & $62.4(57.6-67.2)$ \\
\hline
\end{tabular}

30.0-38.8) and elevated triglycerides was present in 24\% (95\% CI: 19.9-27.9) of the sample population.

\section{Prevalence of nephropathy}

Of the total sample, MA was assessed in 451 patients. The most common reason for missing cases was patients' failure to bring first void urine samples. The analysis of the sample population showed that $12.5 \%$ (95\% CI: $8.1-$ 14.1) had clinical proteinuria; $11.1 \%$ had trace, $1+$ and $2+$ and only $1.4 \%$ had gross proteinuria (3+ or greater). Chronic renal failure was found in 3 patients only. MA was present in $61.2 \%$ (95\% CI: 56.7-65.7) of the sample population. The univariate analysis showed that MA was slightly more frequent in males (53.3\% vs $46.7 \%$ ) compared to females and was significantly higher among overweight and obese compared to the normal weight individuals $(80 \%$ vs $18.8 \%)(p=0.002)$. The presence of MA was statistically significantly associated with presence of chronic complications of DM such as coronary artery disease $(p=0.03)$, diabetic retinopathy $(p=0.07)$ and diabetic neuropathy $(\mathrm{p}=0.01)$. MA was also more common among patients with type 2 DM compared to those 
Table 3: MA in Relation to Baseline Characteristics of the Study Population, in Al Ain District, UAE, 2003-2004 (n = 5 I 3)

\begin{tabular}{|c|c|c|c|c|c|}
\hline \multirow[t]{2}{*}{ Variable name } & \multicolumn{2}{|c|}{ MA Present } & \multicolumn{2}{|c|}{ MA Absent } & \multirow[b]{2}{*}{ p-value } \\
\hline & $\mathbf{n}$ & Percent & $\mathbf{n}$ & Percent & \\
\hline \multicolumn{6}{|l|}{ Sex } \\
\hline Female & 129 & 46.7 & 96 & 54.9 & 0.09 \\
\hline Male & 147 & 53.3 & 79 & 45.1 & \\
\hline \multicolumn{6}{|l|}{ Type of DM } \\
\hline Type I & 42 & 15.8 & 16 & 9.2 & 0.04 \\
\hline Type 2 & 224 & 84.2 & 157 & 90.8 & \\
\hline \multicolumn{6}{|l|}{ BMI } \\
\hline Under weight $(<18.5)$ & I & 0.4 & 4 & 2.4 & 0.002 \\
\hline Healthy weight (18.5-24.99) & 51 & 18.8 & 43 & 25.4 & \\
\hline Overweight (25-29.99) & 98 & 36.2 & 75 & 44.4 & \\
\hline Obese $(>30)$ & $12 \mid$ & 44.6 & 47 & 27.8 & \\
\hline \multicolumn{6}{|l|}{ Nationality } \\
\hline UAE nationals & 209 & $75.7(70.6-80.8)$ & 132 & $75.9(69.5-82.3)$ & 0.09 \\
\hline Gulf countries citizens & 25 & $9.1(5.7-12.5)$ & 23 & $13.2(8.2-18.2)$ & \\
\hline Arabs from other countries & 34 & $12.3(8.4-16.2)$ & 11 & $6.3(2.7-9.9)$ & \\
\hline Asians & 8 & $2.9(0.9-4.9)$ & 8 & $4.6(1.5-7.7)$ & \\
\hline \multicolumn{6}{|l|}{ Coronary Artery Disease } \\
\hline Present & 31 & 11.4 & 32 & 18.4 & 0.03 \\
\hline Absent & 242 & 88.6 & 142 & 81.6 & \\
\hline \multicolumn{6}{|l|}{ Neuropathy } \\
\hline Present & 118 & 42.9 & 52 & 31 & 0.01 \\
\hline Absent & 157 & 57.1 & 116 & 96 & \\
\hline \multicolumn{6}{|l|}{ Retinopathy } \\
\hline Present & 28 & 15.2 & 27 & 23.5 & 0.07 \\
\hline Absent & 156 & 84.8 & 88 & 76.5 & \\
\hline
\end{tabular}

with type 1 , and the results were statistically significant $(\mathrm{p}$ $<0.04$ ) (Table 3). The prevalence of MA showed no statistically significant associations with other covariates, including patient's age, nationality, disease duration, and presence of hypertension, dyslipidaemia or glycemic control.

A backward stepwise multiple logistic regression analysis with backward selection of factors that might independently be associated with development of microalbuminuria was performed on a number of predictors including, type of DM, age group, sex, DM duration (in years), nationality, BMI group, presence of coronary artery disease, diabetic retinopathy and diabetic neuropathy. The results demonstrated a statistically significant association between MA and the following covariates: male sex (adjusted OR: 0.48; 95\% CI: 0.267-0.893), type 2 DM (adjusted OR: 4.309; 95\% CI: 1.590-11.673), high BMI (adjusted OR: $0.614 ; 95 \% \mathrm{CI}: 0.421-0.897)$, UAE nationality (adjusted OR: 0.706; 95\% CI: 0.512-0.972), presence of diabetic neuropathy (adjusted OR: 5.811; 95\% CI: 3.040-11.106) and retinopathy (adjusted OR: 2.800; 95\% CI: 1.303-6.017) (Table 4). Patient age, disease duration, and presence of coronary artery disease were not significantly associated with $\mathrm{MA}$ and as such were removed by the model from the equation.

Table 4: Multivariate Analysis of Predictors for MA among DM Patients in Al-Ain District, UAE, 2003-2004 using stepwise Logistic Regression

\begin{tabular}{lcccc}
\hline Variable & Regression coefficient & P value & Adjusted OR & 95\% Cl \\
\hline Male gender & -0.717 & 0.02 & 0.488 & $0.267-0.893$ \\
Type 2 DM & 1.461 & 0.004 & 4.309 & $1.590-11.673$ \\
UAE Nationality & -0.348 & 0.033 & 0.706 & $0.512-0.972$ \\
High BMI & -0.487 & 0.012 & 0.614 & $0.421-0.897$ \\
Presence of DR & 1.030 & 0.008 & 2.800 & $1.303-6.017$ \\
Presence of DN & 1.760 & 0.000 & 5.811 & $3.040-11.106$ \\
\hline
\end{tabular}

DR-Diabetic Retinopathy. DN-Diabetic Neuropathy 


\section{Discussion}

Diabetic nephropathy defined clinically as the presence of MA or overt nephropathy in patients with diabetes who lack indicators of other renal disease, is the most common cause of renal failure in the industrialized countries [4] and is now considered the commonest cause of ESRD worldwide. It is also widely acknowledged as an independent risk factor for cardiovascular disease [5]. MA is the first clinically detectable stage of involvement of the kidney, and affects between $20-40 \%$ of diabetic patients. Several epidemiological studies reported prevalence rates of MA ranging between $8-32 \%$ among type 2 diabetic Asian patients $[19,20]$. The variation in prevalence rates is most probably attributable to differences in diagnostic criteria, the stage of the disease, the method of assessment and ethnicity [21].

This study is the first cross sectional analysis assessing the prevalence of MA among diabetic patients in the UAE. The analysis showed an overall prevalence rate of MA amounting to $61 \%$ among the sample patients. This rate was clearly higher than the equivalent rates reported in the Arabian Gulf countries [22-24] and the differences could be attributed to the method of assessment or study design.

It is established that once MA is present, it is most likely to progress to proteinuria, over the next 5-10 years, in 20$50 \%$ of subjects. With the presence of MA, it is known that the decline in renal function varies but the average loss in glomerular filtration remains around $10-12 \mathrm{ml} / \mathrm{min} /$ year [25], and is accelerated by hypertension [26], though it is potentially reversible [27]. MA is also strongly associated with traditional cardiovascular risk factors and cardiovascular complications and events. Mogensen et al (1984) reported a significant increase in cardiovascular and total mortality in subjects with type 2 diabetes who had MA [28]. Dineen and Gerstein drew similar conclusions from a meta-analysis of 11 longitudinal studies [29]. MA is also associated with other diabetes complications such as retinopathy and neuropathy [30-33]. The association is held even after adjustment for other cardiovascular risk factors such as age, hypertension, smoking, dyslipidemia, abdominal obesity and hyperglycemia [34].

Similar to studies elsewhere, this study confirm that MA is statistically significantly associated with some adverse cardiovascular risk profile [35-38]. The univariate analysis showed that MA is significantly associated with the presence of coronary artery disease, diabetic retinopathy and neuropathy; though the latter was of borderline significance $(p=0.07)$. However, the multivariate logistic regression analysis demonstrated strong associations between MA and DM retinopathy (adjusted OR: 2.800; 95\% CI: 1.303-6.017) and MA and DM neuropathy (adjusted OR: 5.811; 95\% CI: 3.040-11.106).
Several risk factors have been identified for the presence of MA after adjustment for age and sex. Of significant importance were type 2 DM, UAE nationality, male sex, and obesity. As pointed out earlier, the results of many studies in other populations have shown that type $2 \mathrm{DM}$ is commonly associated with higher prevalence of nephropathy [28]. Similarly, obesity, specifically with central fat distribution, is commonly known to be associated with urinary albumin excretion independent of blood pressure and plasma glucose [39-42].

Many studies have shown statistically significant associations between MA and insulin resistance [43] and the WHO definition of metabolic syndrome lists MA as one of the important components of the syndrome. Generally, our results were consistent with the findings of those studies $[44,45]$. However, our data showed no significant association between presence of MA and some known risk factors such as hypertension, degree of glycemic control, age and duration of diabetes. This could be attributed to the fact that our study was cross-sectional and as such its results cannot be used to correctly trace or establish the role for any of these factors in the development of MA in the sample patients.

The study has few limitations. Firstly, sampling from clinics may not be representative to all patients and/or the general population as undiagnosed subjects may be excluded. Secondly, the design was cross-sectional and therefore, causal relationships cannot be ascertained. Thirdly, it is known that DM is notoriously under-diagnosed, and therefore, the results shown might reflect only the tip of the iceberg. Fourthly, the proxy definition of DM was used in the study and auto antibodies screening such as Anti-GAD analyses was not assessed for all patients. As such it is likely that some type 2 diabetes are misclassified as type 1. Finally, the data from patients in Al-Ain may not represent all patients living in other parts of the UAE regions.

\section{Conclusion}

In conclusion, the fact that MA could lead to adverse outcomes in patients, and the recognition that the risk factors for MA and its clinical course are amenable to intervention, provide a genuine case for action. MA is often incipient and can only be detected by special tests, such as the annual screening for MA, recommended by the American Diabetes Association, which is highly cost-effective. The availability of highly sensitive, cheap, dip-stick technology, strengthens the case for regular screening. Early detection of diabetic nephropathy, adoption of multifactorial interventions targeting its main risk factors and the use of renal-protective agents such as ACE inhibitors might reduce the progression of renal disease. Treatment of hypertension is a priority and the early attention to these 
measures will also ensure the reduction of cardiovascular mortality among diabetic patients.

\section{Competing interests}

The author(s) declare that they have no competing interests.

\section{Authors' contributions}

FA-M conceived the need for the survey in the UAE, participated in its design, and contributed to the interpretation of the results. ME-S, participated in the design of the study and the data analysis. OEN contributed to formulation of research question, manuscript reviews and data interpretation. FA-M and ME-S, OEN collaborated in writing up the manuscript. All authors read and approved the final manuscript.

\section{Acknowledgements}

Our special thanks are extended to the staff doctors and nurses at PHCs of Al-Ain district for their invaluable contribution in implementing the study. Our special thanks extend to Mr. Hussain El-Ajab at the UAE University, for his help with data analysis. Special thanks are extended to Dr. Juma Al-Kaabi for revising and correcting the manuscript and to Prof. Nichollas Nagelkerke for extending statistical advice and help. This work was financially supported by the UAE University under the contract number: 02-8-1।-02.

\section{References}

I. World Health Organization: WHO Expert Committee on Diabetes Mellitus. Second Report, Geneva, WHO Technical Report Series 1980, 646:8-12.

2. International Diabetes Federation (IDF) Atlas [http:// www.eatlas.idf.org/Complications/]

3. Goeree R, Manalich J, Grootendorst P, Beecroft ML, Churchill DN: Cost analysis of dialysis treatments for end-stage renal disease (ESRD). Clin Invest Med 1995, I 8(6):455-64.

4. Canadian Organ Replacement (CORR): 200 I Annual Report. Ottawa, ON, Canada: Canadian Institute for Health Information; 2001.

5. Obineche EN, Adem Abu: Update in Diabetic Nephropathy. Int J Diabetes \& Metabolism 2005, I 3: I-9.

6. Churchill DN, Torrance GW, Taylor DW, Barnes CC, Ludwin D, Shimizu A, Smith EK: Measurement of quality of life in endstage renal disease: the time trade-off approach. Clin Invest Med 1987, IO(I): 14-20.

7. Nicholos RL, Diabetic Kidney Disease: Preventing dialysis \& transplantation. Clinical Diabetes 2003, 21:55-62.

8. Bruno G, Merletti F, Biggeri A, Bargero G, Ferrero S, Pagano G, Cavallo Perin P, Casale Monferrato Study: Progression to overt nephropathy in type 2 diabetes: the Casale Monferrato Study. Diabetes Care 2003, 26(7):2150-5.

9. Mogensen CE, Viberti GC, Peheim E, Kutter D, Hasslacher C, Hofmann W, Renner R, Bojestig M, Poulsen PL, Scott G, Thoma J, Kuefer J. Nilsson B, Gambke B, Mueller P, Steinbiss J, Willamowski KD: Multicenter evaluation of the Micral-Test II test strip, an immunologic rapid test for the detection of microalbuminuria. Diabetes Care 1997, 20(I I):1642-6.

10. American Diabetes Association: Nephropathy in diabetes. Diabetes Care 2004, 27(suppI I):S79-S83.

11. Gerber LM, Johnston K, Alderman MH: Assessment of a new dipstick test in screening for microalbuminuria in patients with hypertension. Am / Hypertens 1998, I I I I Pt I): I32I-7.

12. Incerti J, Zelmanovitz T, Camargo JL, Gross JL, de Azevedo MJ: Evaluation of tests for microalbuminuria screening in patients with diabetes. Nephrol Dial Transplant 2005, 20(I I):2402-7. Epub 2005 Aug 16
13. Spooren PF, Lekkerkerker JF, Vermes I: Micral-Test: a qualitative dipstick test for micro-albuminuria. Diabetes Res Clin Pract 1992, I 8:83-7.

14. World Health Organisation: Definitions, diagnosis and classification of diabetes mellitus and its complications. Report of a WHO consultation. WHO/NCD/NCS/99.2. Geneva; WHO.

15. WHO expert consultation: Appropriate body-mass index for Asian populations and its implications for policy and intervention strategies. The Lancet 2004, 363:157-163.

16. Wallach Jacques: Interpretation of Diagnostic Tests. 8th edition. 2006

17. Meijer JW, Smit AJ, Sonderen EV, Groothoff JW, Eisma WH, Links TP. Symptom scoring systems to diagnose distal polyneuropathy in diabetes: the Diabetic Neuropathy Symptom score. Diabet Med 2002, I 9(I I):962-5.

18. Meijer JW, van Sonderen E, Blaauwwiekel EE, Smit AJ, Groothoff JW, Eisma WH, Links TP: Diabetic neuropathy examination: a hierarchical scoring system to diagnose distal polyneuropathy in diabetes. Diabetes Care 2000, 23(6):750-3.

19. Gupta DK, Verma LK, Khosla PK, Dash SC: The prevalence of microalbuminuria in diabetes: a study from north India. Diabetes Res Clin Pract 1991, I 2(2): 125-8.

20. Allawi J, Rao PV, Gilbert R, Scott G, Jarrett RJ, Keen H, Viberti GC Mather HM: Microalbuminuria in non-insulin-dependent diabetes: its prevalence in Indian compared with Europid patients. Br Med J (Clin Res Ed) 296(6620):462-4. 1988 Feb I3

21. Burden AC, McNally PG, Feehally J, Walls J: Increased incidence of end-stage renal failure secondary to diabetes mellitus in Asian ethnic groups in the United Kingdom. Diabet Med 1992, 9(7):64I-5.

22. Al-Homrami MA, Abdelmoneim I: Significance of proteinuria in type 2 diabetic patients treated at a primary health care center in Abha City, Saudi Arabia. West Afr J Med 2004, 23(3):2II-4.

23. ALZaid AA, Sobki S, DeSilva V: Prevalence of microalbuminuria in Saudi Arabians with non-insulin-dependent diabetes mellitus: a clinic-based study. Diabetes Res Clin Pract 26(2): I I 5-20. 1994 Dec 16

24. Al-Futaisi A, Al-Zakwani I, Almahrezi A, Al-Hajri R, Al-Hashmi L, AlMuniri A, Farooqui M: Prevalence and predictors of microalbuminuria in patients with type 2 diabetes mellitus: a cross-sectional observational study in Oman. Diabetes Res Clin Pract 2006, 72(2):2 2-5. Epub 2005 Nov 8

25. Ritz E, Orth SR: Nephropathy in patients with type 2 diabetes mellitus. N Engl ] Med 34 I(I5): I I27-33. 1999 Oct 7

26. Gall MA, Hougaard P, Borch-Johnsen K, Parving HH: Risk factors for development of incipient and overt diabetic nephropathy in patients with non-insulin dependent diabetes mellitus: prospective, observational study. BMJ 314(7083):783-8. 1997 Mar 15

27. American Diabetes Association: Diabetic nephropathy. Diabetes Care 2003, 26:S94-S98.

28. Mogensen CE: Microalbuminuria predicts clinical proteinuria and early mortality in maturity-onset diabetes. $N$ Engl $\mathrm{J} M e d$ 310(6):356-60. $1984 \mathrm{Feb} 9$

29. Dineen SF, Gerstein HC: The association of microalbuminuria and mortality in non-insulin-dependent diabetes mellitus. A systematic overview of the literature. Arch Intern Med I57(13): |4|3-8. 1997 Jul I4

30. Mann JF, YiQI, Gerstein HC: Albuminuria as a predictor of cardiovascular and renal outcomes in people with known atherosclerotic cardiovascular disease. Kidney Int Suppl 2004:S59-62.

31. Gerstein HC, Mann JF, Yi Q, Zinman B, Dinneen SF, Hoogwerf B Halle JP, Young J, Rashkow A, Joyce C, Nawaz S, Yusuf S, HOPE Study Investigators: Albuminuria and risk of cardiovascular events, death, and heart failure in diabetic and nondiabetic individuals. JAMA 286(4):42I-6. 200 I Jul 25

32. Verhave JC, Hillege HL, Burgerhof JG, Navis G, de Zeeuw D, de Jong PE, PREVEND Study Group: Cardiovascular risk factors are differently associated with urinary albumin excretion in men and women. J Am Soc Nephrol 2003, 14(5): 1330-5.

33. Czekalski S: Diabetic nephropathy and cardiovascular diseases. Rocz Akad Med Bialymst 2005, 50:122-5. 
34. Tagle R, Acevedo M, Vidit DG: Microalbuminuria: is it a valid predictor of cardiovascular risk? Cleve Clin J Med 2003, 70(3):255-6I.

35. Manaviat MR, Afkhami M, Shoja MR: Retinopathy and microalbuminuria in type II diabetic patients. BMC Opthalmology 4:9. 2004 Jul I

36. Ahmedani MY, Hydrie MZ, lqbal A, Gul A, Mirza WB, Basit A: Prevalence of Microalbuminuria in type 2 diabetic patients In Karachi: Pakistan: a multi-center study. J Pak Med Assoc 2005, 55(9):382-6.

37. Herrera-Pombo JL, Aguilar-Diosdado M, Hawkins F, Campos MM, Moreno A, Garcia-Hernandez A, Castro E, Garcia-Doncel LG, Serraclara A, Sanchez-Malo C, Escobar-Jimenez F: Is increasing urinary albumin a better marker for microvascular than for macrovascular complication of type $\mathbf{2}$ diabetes mellitus? Nephron Clin Pract 2005, I0I(3):cl I6-2I. Epub 2005 Jul 5

38. Parving HH, Lewis JB, Ravid M, Remuzzi G, Hunsicker LG, Demand investigators: Prevalence and risk factors for microalbuminuria in a referred cohort of type II diabetic patients: a global perspective. Kidney Int 2006, 69( I I):2057-63.

39. Wu AY, Kong NC, de Leon FA, Pan CY, Tai TY, Yeung VT, Yoo S , Rouillon A, Weir MR: An alarmingly high prevalence of diabetic nephropathy in Asian type 2 diabetic patients: the MicroAlbuminuria Prevalence (MAP) Study. Diabetologia 2005, 48(I): 17-26. Epub 2004 Dec 23

40. de Jong PE, Verhave JC, Pinto-Sietsma SJ, Hillege HL, PREVEND study group: Obesity and target organ damage: the kidney. Int J Obes Relat Metab Disord 2002, 26(Suppl 4):S2I-4.

4I. Liese AD, Hense HW, Döring A, Stieber J, Keil U: Microalbuminuria, central adiposity and hypertension in the non-diabetic urban population of the MONICA Augsburg survey 1994/95. J Hum Hypertens 200I, I 5( I I):799-804.

42. Mulyadi L, Stevens C, Munro S, Lingard J, Bermingham M: Body fat distribution and total body fat as risk factors for microalbuminuria in the obese. Ann Nutr Metab 200I, 45(2):67-7I.

43. Mykkanen L, Haffner SM, Kuusisto J, Pyorala K, Laakso M: Microalbuminuria precedes the development of NIDDM. Diabetes 1994, 43(4):552-7.

44. Viswanathan M, Snehalatha C, Bhattacharyya PK, Mohan V, Ramachandran A: Microalbuminuria in NIDDM patients in south India. Indian J Med Res 1991, 94:125-9.

45. Jerums G, Maclasaac RJ: Treatment of microalbuminuria in patients with type 2 diabetes mellitus. Treat Endocrinol 2002, I(3): 163-73.

\section{Pre-publication history}

The pre-publication history for this paper can be accessed here:

http://www.biomedcentral.com/1471-2369/9/1/prepub

\section{Publish with Bio Med Central and every scientist can read your work free of charge}

"BioMed Central will be the most significant development for disseminating the results of biomedical research in our lifetime. "

Sir Paul Nurse, Cancer Research UK

Your research papers will be:

- available free of charge to the entire biomedical community

- peer reviewed and published immediately upon acceptance

- cited in PubMed and archived on PubMed Central

- yours - you keep the copyright 